\title{
How Do Risk Environment Factors Influence Perpetration of Partner Violence among Male Migrant and Non-migrant Market Workers in Central Asia?
}

\author{
Louisa Gilbert • Lynn Michalopoulos • Xin Ma • Tina Jiwatram-Negrón • \\ Assel Terlikbayeva • Sholpan Primbetova • Tara McCrimmon • Mingway Chang • \\ Timothy Hunt $\cdot$ Stacey A. Shaw $\cdot$ Gaukhar Mergenova
}

Published online: 19 September 2018

(C) The New York Academy of Medicine 2018, corrected publication October/2018

\begin{abstract}
Intimate partner violence (IPV) has emerged as a serious public health issue in migrant communities in Central Asia and globally. To date, however, research on risk factors associated with male perpetration of IPV among migrants remains scant. This study aims to examine risk environment theory-driven factors associated with male perpetration of IPV in the prior 6 months. We recruited, enrolled, and surveyed a respondent-driven sample of 1342 male market workers in Almaty,
\end{abstract}

The original article has been corrected: The surname of coauthor Lynn Michalopoulos was misspelled (as "Michalopolous") in this article as originally published.

L. Gilbert $(\bowtie) \cdot$ A. Terlikbayeva $\cdot$ S. Primbetova

T. McCrimmon $\cdot$ M. Chang $\cdot$ T. Hunt $\cdot$ G. Mergenova

Global Health Research Center of Central Asia, 38B Shashkina

St., Almaty, Kazakhstan

e-mail: lg123@columbia.edu

\author{
A. Terlikbayeva \\ e-mail: assel.terlikbayeva@ghrcca.org \\ S. Primbetova \\ e-mail: sholpan.primbetova@ghrcca.org \\ T. McCrimmon \\ e-mail: trm2131@ columbia.edu \\ M. Chang \\ e-mail: mpc2004@columbia.edu \\ T. Hunt \\ e-mail: th2258@columbia.edu \\ G. Mergenova \\ e-mail: gaukhar.mergenova@ghrcca.org
}

Kazakhstan, that included 562 (42\%) non-migrants defined as Kazakhstan citizens who reside in Almaty; 502 (37\%) external migrants from Kyrgyzstan, Tajikistan, or Uzbekistan; and 278 (21\%) internal migrants from other areas of Kazakhstan. We conducted multivariate logistic regressions to estimate the effects of physical, economic, and political risk environment factors on IPV perpetration by migration status after controlling for potentially confounding socio-demographic and psychosocial

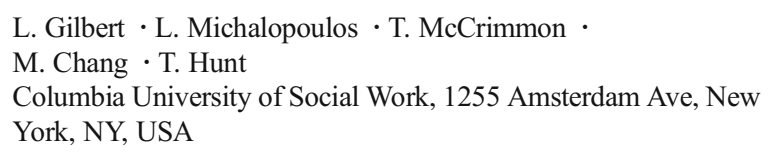

L. Michalopoulos

e-mail: 1m2996@columbia.edu

X. Ma

Emory University Rollins School of Public Health, 1518 Clifton Rd, Atlanta, GA, USA

e-mail: maxinatpku@gmail.com

\section{T. Jiwatram-Negrón}

School of Social Work, Arizona State University, 411 N.Central Avenue, Phoenix, AZ, USA

e-mail: jiwatram@asu.edu

\section{S. A. Shaw}

Brigham Young University School of Social Work, Provo, UT, USA

e-mail: Stacey_shaw@byu.edu 
variables. A total of 170 participants (12.7\%) reported ever perpetrating physical or sexual IPV and $6.7 \%$ perpetrated such IPV in the prior 6 months. Multiple logistic regression results suggest that the risk environment factors of poor living conditions, exposure to political violence, and deportation experiences are associated with IPV perpetration among external and internal migrants, but not among non-migrants. Food insecurity is associated with IPV perpetration among external migrants and non-migrants, but not among internal migrants. Homelessness and arrests by police are associated with IPV perpetration among internal migrants, but not among external migrants or non-migrants. These findings underscore the need to consider the unique combination of risk environment factors that contribute to male IPV perpetration in the design of programs and policies to address IPV perpetration among external and internal migrant and non-migrant men in Central Asia

Keywords Migration · Risk environment - Intimate partner violence $\cdot$ Political violence $\cdot$ Central Asia

\section{Introduction}

Intimate partner violence (IPV) in migrant communities has emerged as a serious public health issue with myriad adverse health consequences in Central Asia and globally [1-7]. To date, however, research on risk factors associated with male perpetration of IPV among migrants remains scant. Most studies on IPV among migrants have addressed the issue from the perspective of women as victims. There is a critical need to approach IPV from the perspective of migrant men as perpetrators as well as to identify risk environment factors that influence perpetration of IPV in migrant communities. Identifying such risk environment factors can inform programs and policies that may have greater public health impact in preventing IPV among migrants. This study aims to examine the role of risk environment factors using a risk environment conceptual framework [8] on perpetration of IPV among a large respondent-driven comparative sample of male market workers in Kazakhstan that includes external labor migrants from Kyrgyzstan, Tajikistan, and Uzbekistan, internal labor migrants from other regions of Kazakhstan, and non-migrant market workers who are residents of Almaty, Kazakhstan.

In Central Asia, there remains an absence of data on the prevalence of male perpetration of IPV among migrants, despite mass migration trends and high rates of IPV victimization found among women in the region [1]. An estimated $20-30 \%$ of adults of Uzbekistan, Tajikistan, and Kyrgyzstan, which are the main suppliers of migrant labor to Kazakhstan, are working outside of their countries [9-11] Kazakhstan ranks number 16 in the world as a host a country for migrants with $20 \%$ of its population identifying as immigrants, [9]. WHO Demographic and Health Surveys indicate that Central Asia has the highest regional rates of violence against women in the world, with nearly half of the women $(47 \%)$ reporting experiencing any physical or sexual violence [1]. The mass migration trends and widespread epidemic of IPV in Central Asia underscore the need to identify risk environment factors associated with male perpetration of IPV among external and internal migrants in this region.

The Risk Environment Conceptual Framework [8] offers a heuristic perspective for identifying overlapping physical, economic, social, and political risk environment factors associated with IPV perpetration among migrants. This framework has been applied extensively to examining how selected factors exogenous to individuals have fueled the HIV epidemic $[12,13]$ and more recently to gender-based violence [14]. The key risk environment factors selected for this investigation are focused on middle range or meso-level factors that may be modifiable by structural or community-level interventions [15], which prior research or theory have linked to IPV in migrant communities around the world. These include a range of physical, economic, and political risk environment factors, such as poor living conditions, mobility, poverty, aggressive policing, and political violence $[7,16,17]$. These meso-level risk environment factors may also indirectly increase the likelihood of perpetration of IPV by increasing the risk of alcohol misuse, depression, and social isolation or other wellestablished microsystem psychosocial factors that are strongly associated with perpetration of IPV $[16,18]$.

Although research on risk environment factors associated with IPV perpetration among migrants remains nascent, accumulating evidence worldwide suggests that poor living conditions, food insecurity, and other aspects of extreme poverty are associated with IPV perpetration among non-migrant populations [19, 20]. In Central Asia, labor migrants often reside in unstable, crowded, and harsh living conditions, including a lack of heating, running water, and electricity [21]. Furthermore, migration often leads to 
geographically stretched and highly mobile households with members who work and reside in different countries [6]. The separation and disruption of intimate partnerships that often occurs during migration may increase the likelihood of an extra relationship affair for one or both partners, which may trigger IPV $[22,23]$.

The physical environment of traveling and crossing borders may also increase the likelihood of experiencing aggressive policing by immigration officials, deportation threats and experiences, and incarceration, which may further contribute to IPV perpetration. External migrants coming from other Central Asian countries as well as internal migrants from Kazakhstan are often fleeing politically repressive regimes or internal ethnic strife [24] and have experienced political threats, been arrested or incarcerated for political beliefs or actions, or been tortured by the police or military. The threat and experience of being deported or arrested continue to shape the postmigration political risk environment for migrants, particularly among highly mobile migrants who routinely cross borders [4]. Although the relationship between political violence and perpetration of IPV among migrants remains largely understudied, one study of 379 immigrant men from the Caribbean and Cape Verde in Boston found that exposure to political violence significantly increased risks for perpetration of sexual and physical violence [4]. Furthermore, the trauma from experiencing political violence as well as the exposure to poor living conditions and other migration risk environment factors may further exert indirect effects on IPV by increasing likelihood of alcohol misuse, depression, or social isolation, all of which are strongly associated with IPV perpetration $[17,25,26]$.

In view of the limited knowledge about risk environment factors associated with perpetration of IPV, this study of a large respondent-driven sample of male market workers in Kazakhstan, including external migrants, internal migrants, and non-migrants, aims to (1) estimate and compare lifetime and recent (past 6 months) prevalence of male perpetration of IPV among these three migrant groups and (2) examine whether meso-level physical, economic, and political risk environment factors are associated with perpetration of recent IPV by migrant status after adjusting for potentially confounding socio-demographic and psychosocial factors.

\section{Methods}

\section{Overview}

Data for this cross-sectional study were collected from the Silk Road Health Project, which was conducted from May 2009 to May 2012. Here, we briefly describe the study design, the respondent-driven sampling (RDS) strategy, and study procedures. Further details on the study are described in a prior publication [21].

Study Design, Sampling Strategy, and Study Population

We employed RDS to recruit and enroll a total sample of 1342 eligible male participants from the Baraholka Market in Almaty, Kazakhstan, which represents one of the largest market places in Central Asia with over 30,000 vendor stalls. The sample of 1342 eligible participants included 562 (42\%) non-migrants defined as Kazakhstan citizens who reside within a two hour commuting distance of Almaty, 502 (37\%) external migrants, who were citizens of other Central Asian countries of Kyrgyzstan, Tajikistan, or Uzbekistan, and 278 (21\%) internal migrants, defined as citizens of Kazakhstan who had a permanent legal address or "propiska" (registration) that was located a commuting distance of two or more hours away. This distance criterion was employed to target workers who maintain a temporary residence in Almaty and permanent homes in other areas of Kazakhstan. As non-registered residents of Almaty, internal and external migrants are not eligible to receive health care and most social services or work in local public sector jobs.

To initiate recruitment of participants for the RDS sample, we selected 14 seed participants from five different migrant groups who met study eligibility criteria, which included non-migrants, internal migrants, and migrants from Kyrgyzstan, Tajikistan, and Uzbekistan that comprised the external migrant group. Each seed participant received three coupons to give to other potential participants they recruited. After participants were enrolled in the study, they also received coupons to invite three additional potential participants. The sample required six waves to reach equilibrium and we enrolled $88 \%$ of the sample at the sixth or subsequent wave [21].

We used a homophily index to measure the degree to which the three migrant groups recruited from their own group rather than from random mixing. The homophily index for non-migrants indicates a $28 \%$ probability that non-migrants recruited other non-migrants, and a $72 \%$ 
probability that non-migrants recruited others at random, suggesting within-group ties exist as well as a large percentage of random mixing across migrant groups. The homophily indexes for internal migrants indicate that they have a $20 \%$ probability to recruit other internal migrants (within group) and external migrants have a $69 \%$ probability to recruit other external migrants (within group). These findings suggest that external migrants have a higher probability of recruiting from their own groups compared to internal migrants or nonmigrants.

\section{Procedures}

Columbia University and the Kazakhstan School of Public Health IRBs approved all study procedures. Research assistants conducted face-to-face screening interviews with potential participants to determine eligibility for the study. Eligibility criteria included the following: (1) identifying as male aged 18 or over; (2) having a valid study recruitment coupon; (3) being employed at the Baraholka Market in the past week; (4) demonstrating fluency in Russian, Kazakh, or Tajik; and (5) being a citizen of Kazakhstan, Kyrgyzstan, Tajikistan, or Uzbekistan. Eligible consenting individuals were enrolled and research assistants administered an audio computerassisted self-interview (ACASI) in a private field office in the market. Participants received \$1 USD in local currency for completing the screening interview, $\$ 5$ USD for each person that they referred to the study using their coupons, and \$10 USD for completing the survey.

\section{Measures}

The ACASI survey covered perpetration of IPV, main exposure variables of risk environment factors, potentially confounding microsystem psychosocial factors (i.e., hazardous drinking, childhood sexual abuse, depression, and lack of social support), socio-demographics, and migration status.

Socio-demographic characteristics included age, marital status, education, parental status (i.e., having children under the age of 18), and religion (i.e., Muslim vs. non-Muslim).

Perpetration of physical and sexual IPV: The subscales of the Revised Conflict Tactics Scales (CTS2) were used to assess the prevalence of any sexual or physical perpetration of IPV against a female intimate partner (i.e., spouse, girlfriend, regular sexual partner) in the past 6 months and over their lifetime using dichotomous yes/no responses. Internal consistency of the CTS2 subscales ranges between 0.79 and 0.95 [27].

Migration status: We categorized three mutually exclusive groups based on migrant status: external migrants who are citizens of Kyrgyzstan, Tajikistan, or Uzbekistan and do not have citizenship in Kazakhstan, internal migrants who are citizens of Kazakhstan but who have a registered permanent residence that is two hours or more commuting distance from Baraholka market, and nonmigrants who are citizens of Kazakhstan and have a permanent residence two hours or less commuting distance from the market.

\section{Meso-level risk environment factors}

Below are risk environment variables included in this study. All variables used dichotomous "Yes $=1 / \mathrm{No}=0$ " response codes, except for monthly income which was coded as a continuous variable.

\section{Physical Risk Environment}

Poor living conditions: We asked participants four questions regarding living conditions in their Almaty residence, including whether or not it had running water, electricity, a toilet, or heating. If participants indicated "Yes=1" in response to not having any of these four items, they were coded as having poor living conditions. Homelessness: We asked participants whether or not they had been without a place to sleep in the past 90 days. Mobility: We asked participants whether or not they had traveled two or more hours away from Barakholka market in the past year.

\section{Economic Risk Environment}

Income level: Income was calculated based on whether a participant's monthly income was above or below the living wage in Kazakhstan, which was identified as 15,999 tenge (\$108 USD) in 2011 [28].

Food insecurity: We asked participants whether or not they had been without sufficient money for food in the past 90 days. 


\section{Political Risk Environment}

Experience of political violence: We asked whether or not participants had ever been arrested, incarcerated, or beaten up for their political activities or beliefs.

Deportation threats and experiences: We asked participants whether or not they had ever been deported, threatened to be deported, or feared being deported.

Arrest by migration police: We asked whether or not participants had ever been arrested by migration police.

\section{Potentially Confounding Microsystem Psychosocial} Factors

Childhood sexual abuse (CSA): Two items from the Stressful Life Events Questionnaire [29] were used to assess if before the age of 16 they had ever been touched or made to touch someone sexually and if before the age of 16 they had ever been physically forced to have intercourse against their will. If a participant said yes to either item, they were categorized as experiencing CSA. Hazardous drinking: Participants scoring eight or higher on the AUDIT (The Alcohol Use Disorders Identification Test) were defined as engaging in hazardous drinking [30].

Depression: The Brief Symptom Inventory (BSI) depression subscale was used to assess depression symptoms [31]. The BSI depression subscale has a reliability of 0.89 [32].

Social support: The Enhancing Recovery in Coronary Heart Disease (ENRICHD) Social Support Instrument (ESSI) [33] was used to evaluate perceived social support. We calculated participants' average scores across the items with higher social support indicated by a higher score.

\section{Data Analysis}

Frequencies and percentages of IPV perpetration ever and in the past 6 months among the three groups are reported. Chi-square tests were conducted to examine differences in lifetime and recent prevalence rates of IPV perpetration by migrant status. Chi-square tests and $t$ tests were also used to examine bivariate associations between independent variables (i.e., risk environment factors, potential psychosocial confounders, and socio-demographics) and perpetration of IPV in the past 6 months.

We conducted multivariate logistic regressions to estimate the effects of risk environment factors on IPV perpetration among external, internal, and non-migrant market workers by including the interaction terms of risk environment factors and migrant group in the regression models. We reported the main effects and their 95\% confidence intervals within each migrant group, adjusting for socio-demographic variables of age, marital status, religion, and parental status and microsystem psychosocial variables of childhood sexual abuse, hazardous drinking, depression, and social support. There were 67 missing cases for the education variable so it was also not included in the model. As the recruitment was conducted using RDS, the RDS individual weights were applied to each regression model. Analyses were performed in SAS 9.3.

Availability of Data and Materials All data is available from the Columbia Academic Commons database (academiccommons.columbia.edu), permanent URL: https://doi.org/10.7916/D8NG4QCW.

\section{Results}

Socio-demographic Characteristics

Of the total sample, $562(42 \%)$ were identified as nonmigrants, $502(37 \%)$ as external migrants, and 278 $(21 \%)$ as internal migrants (see Table 1$)$. The majority were identified as Kazakh (67.5\%), 15.4\% Tajik, 5.7\% Kyrgyz, 4.2\% Karakalpak or Uzbek, 3.1\% Uighur, and the remainder as "other." The mean age was 27.0 years $(\mathrm{SD}=5.3)$. Younger age was associated with perpetration of IPV in the prior 6 months. Almost three quarters (72.6\%) reported having a high school degree or higher education. A total of 586 participants $(43.7 \%)$ were married and about one fourth (26\%) had children under the age of 18 . Not having children was significantly associated with perpetration of IPV in the past 6 months. A total of 107 participants (8\%) indicated that they had ever been in jail or prison. The large majority $(94.1 \%)$ indicated that they were Muslim. Those who identified as Muslim were less likely to report perpetration of IPV than non-Muslims.

Microsystem Psychosocial Characteristics

Of the total sample, $16.4 \%$ engaged in hazardous drinking. A total of 73 participants $(5.5 \%)$ reported having experienced childhood sexual abuse (CSA). Hazardous drinking, higher levels of depression, lower levels of 
Table 1 Bivariate associations between socio-demographic characteristics, meso-level risk environment factors and micro-level psychosocial characteristics associated with perpetration of IPV in past 6 months among the total sample $(N=1340)$

\begin{tabular}{|c|c|c|c|c|}
\hline & $\begin{array}{l}\text { Total sample } \\
(N=1340)\end{array}$ & $\begin{array}{l}\text { Physical/sexual } \\
\text { IPV in past } \\
6 \text { months }(N=90)\end{array}$ & $\begin{array}{l}\text { No IPV in past } \\
6 \text { months }(N=1250)\end{array}$ & $p$ value \\
\hline \multicolumn{5}{|l|}{ Socio-demographics } \\
\hline Age (mean, SD) & $27.0,7.2$ & $24.9,5.3$ & $27.1,7.3$ & $0.0004 * *$ \\
\hline High school or higher education (67 missing) & $925(72.6 \%)$ & $59(68.6 \%)$ & $866(72.8 \%)$ & 0.396 \\
\hline Married & $586(43.7 \%)$ & $36(40.0 \%)$ & $550(44.0 \%)$ & 0.46 \\
\hline Have children under 18 & $354(26.4 \%)$ & $10(11.1 \%)$ & $344(27.5 \%)$ & $0.0006^{* *}$ \\
\hline Ever in jail or prison & $107(8.0 \%)$ & $11(12.2 \%)$ & $96(7.7 \%)$ & 0.1247 \\
\hline Religion-Muslim & $1261(94.1 \%)$ & $80(88.9 \%)$ & $1181(94.5 \%)$ & $0.0296^{*}$ \\
\hline \multicolumn{5}{|l|}{ Meso-level physical, economic, and social risk environment factors } \\
\hline $\begin{array}{l}\text { Poor living conditions (lack any of these amenities: } \\
\text { electricity, running water, toilet, heating) }\end{array}$ & $559(41.7 \%)$ & $58(64.4 \%)$ & $501(40.1 \%)$ & $<0.0001 * *$ \\
\hline Homeless & $181(13.5 \%)$ & $18(20.0 \%)$ & $163(13.0 \%)$ & 0.0621 \\
\hline Traveled outside of Almaty in the past year & $711(53.1 \%)$ & $53(58.9 \%)$ & $658(52.6 \%)$ & 0.2513 \\
\hline Food insecurity & $302(22.5 \%)$ & $34(37.8 \%)$ & $268(21.4 \%)$ & $0.0003 * *$ \\
\hline Income below living wage & $229(17.1 \%)$ & $24(26.7 \%)$ & $205(16.4 \%)$ & $0.0125^{*}$ \\
\hline $\begin{array}{l}\text { Arrested, incarcerated, or beaten up for political activities or } \\
\text { beliefs }\end{array}$ & $58(4.3 \%)$ & $16(17.8 \%)$ & $42(3.4 \%)$ & $<0.0001 * *$ \\
\hline $\begin{array}{l}\text { Deported, threatened to be deported, or feared being } \\
\text { deported }\end{array}$ & $114(8.5 \%)$ & $18(20.0 \%)$ & $96(7.7 \%)$ & $<0.0001^{* *}$ \\
\hline Arrested by migration police & $473(35.3 \%)$ & $36(40.0 \%)$ & $437(35.0 \%)$ & 0.3339 \\
\hline \multicolumn{5}{|l|}{ Microsystem psychosocial factors } \\
\hline Childhood sexual abuse & $73(5.5 \%)$ & $23(25.6 \%)$ & $50(4.0 \%)$ & $<0.0001^{* *}$ \\
\hline Hazardous drinking & $220(16.4 \%)$ & $28(31.1 \%)$ & $192(15.4 \%)$ & $<0.0001^{* *}$ \\
\hline Depression (mean, SD) & $0.7,1.0$ & $1.5,1.3$ & $0.6,1.0$ & $<0.0001^{* *}$ \\
\hline Social support (mean, SD) & $18.8,7.1$ & $15.3,6.5$ & $19.0,7.1$ & $<0.0001^{* *}$ \\
\hline
\end{tabular}

$* p<0.05, * * p<0.01$

social support, and history of CSA were significantly associated with perpetration of IPV in the prior 6 months.

\section{Meso-level Risk Environment Characteristics}

A total of 229 participants $(17.1 \%)$ earned less than a living wage. Of the total sample, $13.5 \%(n=181)$ experienced homelessness in the prior 90 days and $41.7 \%$ $(n=559)$ reported experiencing poor living conditions in the prior 90 days (i.e., lack of running water, toilet, heating, or electricity) (Table 1). More than one fifth $(22 \%, n=302)$ reported they did not have enough money to buy food in the prior 90 days. About half $(53.1 \%$, $n=711$ ) reported traveling more than two hours outside of Almaty in the prior year. Earning below a living wage, poor living conditions, and food insecurity were significantly associated with IPV perpetration.
More than one third $(35.3 \%, n=473)$ indicated that they had ever been arrested by migration police. A total of 58 participants $(4.3 \%)$ reported that they had ever been arrested, incarcerated, or beaten up for their political beliefs. In addition, 8.5\% $(n=114)$ had ever been deported, feared deportation, or were threatened to be deported. A history of being arrested, incarcerated, or beaten up for their political beliefs and experience or threat of deportation were significantly associated with IPV perpetration.

Prevalence of Perpetration of Physical and Sexual IPV by Migration Status

Table 2 presents lifetime and past 6-month prevalence rates of IPV perpetration by migration status. A total of 170 participants $(12.7 \%)$ reported ever perpetrating any 
physical or sexual IPV. Ninety participants $(6.7 \%)$ indicated they perpetrated any physical or sexual IPV in the past 6 months. Non-migrants were more likely to report ever perpetrating physical or sexual IPV compared to external migrants $(15.1 \%$ vs. $9.8 \%, p<0.05)$. However, there were no significant differences in past 6-month IPV prevalence rates by migrant status.

Associations between Risk Environment Characteristics and Perpetration of IPV by Migration Status

Table 3 presents the odds ratios and their associated $95 \%$ confidence intervals from multivariate logistic regressions. The adjusted odds ratios associated with risk environment variables for migrant status were obtained by combining the main effect of the risk environment variable with the associated interaction effect of the risk environment variable and migration status. All models included potentially confounding variables of age, marital status, parental status (i.e., having children under the age of 18), prior incarceration history, religion (Muslim vs. non-Muslim), CSA history, hazardous drinking, depression, and social support.

Socio-demographic and Psychosocial Confounding Factors

Younger age and being married were associated with higher odds of IPV perpetration in all of the logistic models (Table 3). However, having children was associated with lower odds of perpetrating IPV in all of the models. A history of CSA, hazardous drinking, and higher levels of depression were significantly associated with perpetration of IPV in all of the models.

\section{Physical Risk Environment}

Poor living conditions were associated with a greater likelihood of IPV perpetration among external migrants $(\mathrm{aOR}=3.07 ; 95 \% \mathrm{CI}[1.17,8.11])$ and internal migrants $(\mathrm{aOR}=3.07 ; 95 \% \mathrm{CI}[1.04,9.06])$, but not among nonmigrants. Homelessness was also associated with perpetration of IPV among internal migrants $(\mathrm{aOR}=2.95$; $95 \%$ CI $[1.13,7.70])$ but not among external migrants or non-migrants. Mobility was not associated with IPV perpetration in any of the three groups.

\section{Economic Risk Environment}

For non-migrants, earning below a living wage was associated with IPV perpetration for non-migrants ( $\mathrm{aOR}=2.17 ; 95 \%$ CI $[1.16,4.07])$, but not for external migrants or internal migrants. However, food insecurity was associated with IPV perpetration among nonmigrants $(\mathrm{aOR}=2.08 ; 95 \% \mathrm{CI}[1.14,3.81])$ and external migrants $(\mathrm{aOR}=4.37$; $95 \% \mathrm{CI}[1.72,11.07])$, but not among internal migrants.

\section{Political Risk Environment}

Being arrested, incarcerated, or beaten up for political beliefs was associated with higher odds of IPV perpetration among external migrants $(\mathrm{aOR}=15.08 ; 95 \%$ $\mathrm{CI}=3.39,67.07)$ and internal migrants $(\mathrm{aOR}=4.9$; 95\% CI [1.32, 18.26]), but not among non-migrants. Being deported or fearing deportation was associated with perpetration of IPV among external migrants (aOR $=4.13 ; 95 \%$ CI $[1.55,10.99])$, but not among internal migrants or non-migrants. Being arrested by migration police was associated with IPV perpetration among internal migrants $(\mathrm{aOR}=3.34 ; 95 \%$ CI $[1.36$, $8.30]$ ), but not among external migrants or nonmigrants.

\section{Discussion}

To our knowledge, this is the first study that aims to examine meso-level risk environment factors that may be associated with perpetration of IPV among a comparative sample of external and internal migrants as well as non-migrants. Although the lifetime prevalence rates of male perpetration of IPV were significantly higher among non-migrants than internal and external migrants, there were no significant differences in the past 6-month prevalence rates of IPV perpetration among the three groups. The past 6-month prevalence rates for any physical or sexual IPV, which ranged between 5.8 and $7.8 \%$, are similar to past year prevalence rates of IPV victimization found among migrant and non-migrant women in Central Asia [3, 34]. The similarity in prevalence rates of IPV reported by female survivors and male perpetrators suggests the feasibility and utility of obtaining IPV prevalence data from the perspective of male migrants and non-migrants as perpetrators. 
Table 2 Prevalence of perpetration of IPV lifetime and past 6 months by migrant status $(N=1342)$

\begin{tabular}{|c|c|c|c|c|c|c|}
\hline Type of IPV & & $\begin{array}{l}\text { Total } \\
(N=1342)\end{array}$ & $\begin{array}{l}\text { Non-migrant } \\
(n=562)\end{array}$ & $\begin{array}{l}\text { Internal migrant } \\
(n=278)\end{array}$ & $\begin{array}{l}\text { External migrant } \\
(n=502)\end{array}$ & $p$ value \\
\hline \multirow[t]{2}{*}{$\begin{array}{l}\text { Any physical } \\
\text { IPV }\end{array}$} & $\begin{array}{l}\text { Past } \\
\quad 6 \text { months }\end{array}$ & $49(3.7 \%)$ & $26(4.6 \%)$ & $8(2.9 \%)$ & $15(3.0 \%)$ & 0.2738 \\
\hline & Lifetime & $113(8.4 \%)$ & $58(10.3 \%)$ & $24(8.6 \%)$ & $31(6.2 \%)$ & 0.0606 \\
\hline \multirow[t]{2}{*}{ Any sexual IPV } & $\begin{array}{l}\text { Past } \\
\quad 6 \text { months }\end{array}$ & $59(4.4 \%)$ & $24(4.3 \%)$ & $15(5.4 \%)$ & $20(4.0 \%)$ & 0.6482 \\
\hline & Lifetime & $106(7.9 \%)$ & $50(8.9 \%)$ & $26(9.4 \%)$ & $30(6.0 \%)$ & 0.132 \\
\hline \multirow[t]{2}{*}{$\begin{array}{l}\text { Any physical } \\
\text { or sexual IPV }\end{array}$} & $\begin{array}{l}\text { Past } \\
\quad 6 \text { months }\end{array}$ & $90(6.7 \%)$ & $44(7.8 \%)$ & $17(6.1 \%)$ & $29(5.8 \%)$ & 0.3788 \\
\hline & Lifetime & $170(12.7 \%)$ & $85(15.1 \%)$ & $36(13.0 \%)$ & $49(9.8 \%)$ & $0.0335 *$ \\
\hline
\end{tabular}

The multivariate findings indicate that meso-level risk environment characteristics are differentially associated with IPV perpetration among non-migrants and external and internal migrants. The physical risk environment of poor living conditions and homelessness contributes to the context in which male perpetration of IPV occurs among external and internal migrants. However, there was no association between poor living conditions or homelessness and perpetration of IPV found among non-migrants. Economic risk environment factors of food insecurity and earning below the living wage were also differentially associated with perpetration of IPV among the migrant status groups. Food insecurity was associated with perpetration of IPV among external migrants and non-migrants, but not for internal migrants. Whereas earning an income below the living wage was associated with perpetration of IPV among non-migrants, but not for external or internal migrants.

Political risk environment factors exerted strong effects on perpetration of IPV among external and internal migrants, consistent with prior research [4]. Experience, threat or fear of deportation was significantly associated with perpetration of IPV for external migrants, but not for non-migrants or internal migrants. Similarly, being arrested, incarcerated, or beaten up for political activities was associated with perpetration of IPV for both external and internal migrants but not for non-migrants. In addition, internal migrants who reported being arrested by migration police were more likely to perpetrate IPV, compared to their counterparts. Undercover migration police make frequent raids on the market place threatening to arrest or arresting market workers regardless of migration status, often with the expectation of a bribe. This aggressive policing may be particularly humiliating and traumatizing for internal migrant workers who are Kazakhstan citizens.

Consistent with prior meta-analyses [16, 18], alcohol misuse, CSA, and depression were strongly associated with perpetration of IPV across all regression models. These associations suggest the importance of considering how meso-level risk environment factors may synergistically interact with these microsystem factors.

Several limitations need to be considered in interpreting study findings. First, the cross-sectional design precludes any causal inference in interpreting the association between these risk environment factors and perpetration of IPV. Second, the data on perpetration of physical and sexual IPV is self-reported and likely underestimated given perceived negative consequences of disclosing IPV. The underestimation of perpetration of IPV is likely to have yielded lower prevalence rates and reduced the likelihood of finding significant associations between risk environment factors and IPV. Third, study sample was drawn from the Baraholka market, a single large market location in Almaty, Kazakhstan, which limits the generalizability of the study findings. Despite these limitations, this study was strengthened by robust methods to obtain a large respondent-driven comparative sample of external and internal migrants and non-migrants in Central Asia. This study also controlled for a relatively full set of potentially confounding sociodemographic and psychosocial variables.

\section{Conclusions}

This investigation suggests that the combination of physical, economic, and political risk environment 
Table 3 Multivariate associations between meso-level physical, economic, and political risk environment factors and perpetration of IPV by migrant status $(N=1342)$

$* * p<0.010, * p<0.05$

\begin{tabular}{|c|c|c|c|c|c|}
\hline & & OR & $95 \% \mathrm{C}$ & & $p$ value \\
\hline \multirow{12}{*}{$\begin{array}{l}\text { Poor living conditions } \times \text { migrant } \\
\text { status }\end{array}$} & Non-migrant & 1.15 & 0.63 & 2.11 & 0.643 \\
\hline & Internal migrant & 3.07 & 1.04 & 9.06 & $0.042 *$ \\
\hline & External migrant & 3.07 & 1.17 & 8.11 & $0.023^{*}$ \\
\hline & Age & 0.934 & 0.89 & 0.981 & $0.006^{* *}$ \\
\hline & Married & 2.88 & 1.62 & 5.09 & $<0.001 * *$ \\
\hline & $\begin{array}{l}\text { Have children } \\
\text { under } 18\end{array}$ & 0.42 & 0.20 & 0.9 & $0.026^{*}$ \\
\hline & $\begin{array}{l}\text { Ever in jail or } \\
\text { prison }\end{array}$ & 1.19 & 0.486 & 2.92 & 0.701 \\
\hline & Religion-Muslim & 1.55 & 0.663 & 3.64 & 0.311 \\
\hline & $\begin{array}{l}\text { Childhood sexual } \\
\text { abuse }\end{array}$ & 4.77 & 2.27 & 10.04 & $<0.001 * *$ \\
\hline & Hazard drinking & 2.66 & 1.59 & 4.43 & $<0.001 * *$ \\
\hline & Depression & 1.36 & 1.12 & 1.65 & $0.002 * *$ \\
\hline & $\begin{array}{l}\text { Perceived social } \\
\text { support }\end{array}$ & 1.02 & 0.992 & 1.06 & 0.149 \\
\hline \multirow[t]{12}{*}{ Homeless $\times$ migration status } & Non-migrant & 1.49 & 0.67 & 3.30 & 0.323 \\
\hline & Internal migrant & 2.95 & 1.13 & 7.70 & $0.027 *$ \\
\hline & External migrant & 1.01 & 0.35 & 2.87 & 0.987 \\
\hline & Age & 0.927 & 0.884 & 0.973 & $0.002 * *$ \\
\hline & Married & 2.93 & 1.66 & 5.20 & $<0.001 * *$ \\
\hline & $\begin{array}{l}\text { Have children } \\
\text { under } 18\end{array}$ & 0.399 & 0.188 & 0.848 & $0.017 *$ \\
\hline & $\begin{array}{l}\text { Ever in jail or } \\
\text { prison }\end{array}$ & 1.28 & 0.52 & 3.15 & 0.586 \\
\hline & Religion-Muslim & 1.73 & 0.728 & 4.09 & 0.215 \\
\hline & $\begin{array}{l}\text { Childhood sexual } \\
\text { abuse }\end{array}$ & 4.74 & 2.28 & 9.88 & $<0.001 * *$ \\
\hline & $\begin{array}{l}\text { Hazardous } \\
\text { drinking }\end{array}$ & 2.54 & 1.523 & 4.219 & $<0.001 * *$ \\
\hline & Depression & 1.41 & 1.17 & 1.71 & $<0.001 * *$ \\
\hline & Social support & 1.03 & 0.997 & 1.061 & 0.082 \\
\hline \multirow[t]{12}{*}{ Mobility $\times$ migration status } & Non-migrant & 1.31 & 0.72 & 2.37 & 0.373 \\
\hline & Internal & 1.56 & 0.66 & 3.72 & 0.314 \\
\hline & External & 2.36 & 0.88 & 6.35 & 0.089 \\
\hline & Age & 0.934 & 0.89 & 0.979 & $0.005 * *$ \\
\hline & Married & 3.17 & 1.80 & 5.61 & $<0.001 * *$ \\
\hline & $\begin{array}{l}\text { Have children } \\
\quad \text { under } 18\end{array}$ & 0.378 & 0.18 & 0.803 & $0.011 *$ \\
\hline & $\begin{array}{l}\text { Ever in jail or } \\
\text { prison }\end{array}$ & 1.07 & 0.439 & 2.63 & 0.877 \\
\hline & Religion-Muslim & 1.62 & 0.685 & 3.84 & 0.271 \\
\hline & $\begin{array}{l}\text { Childhood sexual } \\
\text { abuse }\end{array}$ & 4.39 & 2.07 & 9.31 & $<0.001 * *$ \\
\hline & $\begin{array}{r}\text { Hazardous } \\
\text { drinking }\end{array}$ & 2.33 & 1.40 & 3.87 & $0.001 * *$ \\
\hline & Depression & 1.39 & 1.15 & 1.68 & $<0.001 * *$ \\
\hline & Social support & 1.02 & 0.988 & 1.05 & 0.235 \\
\hline
\end{tabular}


Table 3 (continued)

\begin{tabular}{|c|c|c|c|c|c|}
\hline & & OR & $95 \% \mathrm{C}$ & & $p$ value \\
\hline \multirow[t]{12}{*}{ Food insecurity $\times$ migrant status } & Non-migrant & 2.08 & 1.14 & 3.81 & $0.018^{*}$ \\
\hline & Internal migrant & 0.43 & 0.13 & 1.36 & 0.151 \\
\hline & External migrant & 4.37 & 1.72 & 11.07 & $0.002 * *$ \\
\hline & Age & 0.929 & 0.886 & 0.973 & $0.002 * *$ \\
\hline & Married & 3.43 & 1.942 & 6.057 & $<0.0001 * *$ \\
\hline & $\begin{array}{l}\text { Have children } \\
\text { under } 18\end{array}$ & 0.387 & 0.182 & 0.824 & $0.014 *$ \\
\hline & $\begin{array}{l}\text { Ever in jail or } \\
\text { prison }\end{array}$ & 1.02 & 0.405 & 2.57 & 0.966 \\
\hline & Religion-Muslim & 1.59 & 0.675 & 3.758 & 0.287 \\
\hline & $\begin{array}{l}\text { Childhood sexual } \\
\text { abuse }\end{array}$ & 5.18 & 2.43 & 11.02 & $<0.0001 * *$ \\
\hline & $\begin{array}{r}\text { Hazardous } \\
\text { drinking }\end{array}$ & 2.58 & 1.55 & 4.30 & $0.0003 * *$ \\
\hline & Depression & 1.35 & 1.12 & 1.64 & $0.002 * *$ \\
\hline & Social support & 1.03 & 0.996 & 1.06 & 0.084 \\
\hline \multirow{12}{*}{$\begin{array}{l}\text { Income below living wage } \times \\
\text { migrant status }\end{array}$} & Non-migrant & 2.17 & 1.16 & 4.07 & $0.016^{*}$ \\
\hline & Internal migrant & 0.22 & 0.05 & 1.07 & 0.061 \\
\hline & External migrant & 0.79 & 0.25 & 2.53 & 0.691 \\
\hline & Age & 0.932 & 0.889 & 0.978 & $0.004 * *$ \\
\hline & Married & 3.08 & 1.75 & 5.44 & $<0.001 * *$ \\
\hline & $\begin{array}{l}\text { Have children } \\
\text { under } 18\end{array}$ & 0.384 & 0.18 & 0.823 & $0.014 *$ \\
\hline & $\begin{array}{l}\text { Ever in jail or } \\
\text { prison }\end{array}$ & 1.07 & 0.438 & 2.61 & 0.881 \\
\hline & Religion-Muslim & 1.53 & 0.65 & 3.61 & 0.330 \\
\hline & $\begin{array}{l}\text { Childhood sexual } \\
\text { abuse }\end{array}$ & 5.59 & 2.68 & 11.65 & $<0.001^{* *}$ \\
\hline & $\begin{array}{r}\text { Hazardous } \\
\text { drinking }\end{array}$ & 2.43 & 1.46 & 4.05 & $<0.001 * *$ \\
\hline & Depression & 1.40 & 1.16 & 1.70 & $<0.001 * *$ \\
\hline & Social support & 1.03 & 0.996 & 1.06 & 0.089 \\
\hline \multirow{12}{*}{$\begin{array}{l}\text { Arrested, incarcerated, or beaten } \\
\text { up for political activities or } \\
\text { beliefs } \times \text { migration status }\end{array}$} & Non-migrant & 1.21 & 0.37 & 3.91 & 0.751 \\
\hline & Internal migrant & 4.90 & 1.32 & 18.26 & $0.018^{*}$ \\
\hline & External migrant & 15.08 & 3.39 & 67.06 & $<0.001 * *$ \\
\hline & Age & 0.928 & 0.885 & 0.973 & $0.002 * *$ \\
\hline & Married & 3.47 & 1.97 & 6.14 & $<0.001 * *$ \\
\hline & $\begin{array}{l}\text { Have children } \\
\text { under } 18\end{array}$ & 0.356 & 0.166 & 0.765 & $0.008 * *$ \\
\hline & $\begin{array}{l}\text { Ever in jail or } \\
\text { prison }\end{array}$ & 0.66 & 0.234 & 1.86 & 0.432 \\
\hline & Religion-Muslim & 1.35 & 0.565 & 3.24 & 0.497 \\
\hline & $\begin{array}{l}\text { Childhood sexual } \\
\text { abuse }\end{array}$ & 3.31 & 1.48 & 7.41 & $0.004 * *$ \\
\hline & $\begin{array}{r}\text { Hazardous } \\
\text { drinking }\end{array}$ & 2.46 & 1.48 & 4.09 & $0.001 * *$ \\
\hline & Depression & 1.35 & 1.11 & 1.64 & $0.003 * *$ \\
\hline & Social support & 1.01 & 0.99 & 1.05 & 0.284 \\
\hline
\end{tabular}


Table 3 (continued)

\begin{tabular}{|c|c|c|c|c|c|}
\hline & & OR & $95 \% \mathrm{C}$ & & $p$ value \\
\hline \multirow{12}{*}{$\begin{array}{l}\text { Deported, threatened to be } \\
\text { deported, or feared being } \\
\text { deported } \times \text { migration status }\end{array}$} & Non-migrant & 0.95 & 0.28 & 3.16 & 0.930 \\
\hline & Internal & 0.78 & 0.21 & 2.90 & 0.713 \\
\hline & External & 4.13 & 1.55 & 10.99 & $0.005 * *$ \\
\hline & Age & 0.929 & 0.886 & 0.974 & $0.002 * *$ \\
\hline & Married & 3.21 & 1.825 & 5.646 & $<0.001 * *$ \\
\hline & $\begin{array}{l}\text { Have children } \\
\text { under } 18\end{array}$ & 0.376 & 0.176 & 0.801 & $0.011 *$ \\
\hline & $\begin{array}{l}\text { Ever in jail or } \\
\text { prison }\end{array}$ & 1.30 & 0.534 & 3.17 & 0.561 \\
\hline & Religion-Muslim & 1.612 & 0.679 & 3.828 & 0.280 \\
\hline & $\begin{array}{l}\text { Childhood sexual } \\
\text { abuse }\end{array}$ & 4.39 & 2.08 & 9.27 & $<0.001 * *$ \\
\hline & $\begin{array}{r}\text { Hazardous } \\
\text { drinking }\end{array}$ & 2.46 & 1.484 & 4.08 & $<0.001 * *$ \\
\hline & Depression & 1.39 & 1.15 & 1.68 & $<0.001 * *$ \\
\hline & Social support & 1.02 & 0.988 & 1.05 & 0.220 \\
\hline \multirow{12}{*}{$\begin{array}{l}\text { Arrested by migration police } \times \\
\text { migration status }\end{array}$} & Non-migrant & 1.10 & 0.55 & 2.21 & 0.786 \\
\hline & Internal migrant & 3.34 & 1.36 & 8.20 & $0.008 * *$ \\
\hline & External migrant & 0.80 & 0.32 & 2.01 & 0.629 \\
\hline & Age & 0.932 & 0.889 & 0.978 & $0.004 * *$ \\
\hline & Married & 2.98 & 1.696 & 5.25 & $<0.001 * *$ \\
\hline & $\begin{array}{l}\text { Have children } \\
\text { under } 18\end{array}$ & 0.404 & 0.19 & 0.859 & $0.019^{*}$ \\
\hline & $\begin{array}{l}\text { Ever in jail or } \\
\text { prison }\end{array}$ & 1.25 & 0.49 & 3.06 & 0.662 \\
\hline & Religion-Muslim & 1.59 & 0.675 & 3.74 & 0.289 \\
\hline & $\begin{array}{l}\text { Childhood sexual } \\
\text { abuse }\end{array}$ & 4.997 & 2.37 & 10.52 & $<0.001 * *$ \\
\hline & $\begin{array}{r}\text { Hazardous } \\
\text { drinking }\end{array}$ & 2.39 & 1.44 & 3.97 & $<0.001 * *$ \\
\hline & Depression & 1.38 & 1.14 & 1.67 & $0.001 * *$ \\
\hline & Social support & 1.03 & 0.993 & 1.06 & 0.131 \\
\hline
\end{tabular}

factors associated with perpetration of IPV varies by migration status. These findings underscore the need for novel community-level and structural interventions that may target the particular set of modifiable meso-level risk environment factors that shape perpetration of IPV among external and internal migrants. Understanding the relative contribution of these risk environment factors may guide the design of programs and policies that not only most effectively prevent male perpetration of IPV for external and internal migrants, but which may also have a broader public health impact. For example, given the strong association between poor living conditions and IPV perpetration among external and internal migrants, it is likely that programs and policies that improve access to water, electricity, and heat in migrant housing would not only reduce risk of IPV but also prevent a host of other mental and physical health problems. Similarly, policies and structural interventions to redress aggressive policing against migrants may not only decrease IPV perpetration but also reduce stress and other health and social consequences associated with exposure to such policing among migrant communities. Further mixed methods research and longitudinal studies are needed to identify more specific mechanisms and processes linking these risk environment factors to perpetration of IPV among different migrant groups in Central Asia and worldwide.

Acknowledgements We deeply appreciate all the market workers who took time out of their long working hours to complete this survey. 
Authors' Contributions LG guided overall conceptual design for the study and preparation of the manuscript.

LM, TJ and SS, TH and TM contributed to the preparation of the manuscript.

AT and SP contributed to the conceptual design and oversaw data collection in the field. XM and $\mathrm{MC}$ conducted statistical analyses. GM contributed to the conceptual design, the preparation of the manuscript and oversaw data collection in the field. All authors read and approved this manuscript.

Funding This study was funded by the National Institute of Mental Health, NIMH R01 MH082684 awarded to Dr. Nabila El-Bassel. The funder was not involved in study design or analysis.

\section{Compliance with Ethical Standards}

Ethics Approval and Consent to Participate This trial was approved by Columbia University's IRB, and by the ethics committee of the Kazakhstan School of Public Health (KSPH).

Informed Consent Informed consent was conducted with all study participants before taking part in screening for study eligibility, and again with all eligible participants before they completed the initial assessments.

\section{References}

1. Palermo T, Bleck J, Peterman A. Tip of the iceberg: reporting and gender-based violence in developing countries. Am J Epidemiol. 2014;179(6):602-12.

2. Camlin CS, Hosegood V, Newell ML, McGrath N, Bärnighausen T, Snow RC. Gender, migration and HIV in rural Kwazulu-Natal, South Africa. PLoS One. 2010;5(7).

3. Gilbert L, Shaw S, Terlikbayeva A, McCrimmon T, Zhussupov B, Ismayilova L. Intimate partner violence and HIV risks among migrant women in Central Asia. J AIDS Clin Res. 2015;6(428):e1000428.

4. Gupta J, Acevedo-Garcia D, Hemenway D, Decker MR, Raj A, Silverman JG. Premigration exposure to political violence and perpetration of intimate partner violence among migrant men in Boston. Am J Public Health. 2009;99(3): 462-9.

5. Midlarsky E, Venkataramani-Kothari A, Plante M. Domestic violence in the Chinese and South Asian immigrant communities. Ann N Y Acad Sci. 2006;1087:279-300.

6. Parrado EA, Flippen CA, McQuiston C. Migration and relationship power among Mexican women. Demography. 2005;42(2):347-72.

7. Raj A, Silverman JG. Immigrant South Asian women at greater risk for injury from intimate partner violence. Am J Public Health. 2003;93(3):435-7.

8. Rhodes T. The 'Risk Environment' : a framework for understanding and reducing drug-related harm. Int J Drug Policy. 2002;13:85-94.
9. IOM. World migration report, 2015. Geneva: International Organization for Migration (IOM; 2015.

10. Sadovskaya E. Kazakhstan in Central Asia migration subsystem. Demoscope. http://demoscope.ru/weekly/2010 /0415/analit04.php; 2010.

11. DiBartolomeo AD, Weinar A. Regional migration report in Russia and Central Asia. EU/RSCAS Migration Center; 2014.

12. Strathdee SA, Hallett TB, Bobrova N, Rhodes T, Booth R, Abdool R, et al. HIV and risk environment for injecting drug users: the past, present, and future. Lancet. 2010;376(9737): 268-84.

13. Rhodes T. Risk environments and drug harms: a social science for harm reduction approach. Int J Drug Policy. 2009;20:193-201.

14. Lorvick J, Lutnick A, Wenger LD, Bourgois P, Cheng H, Kral AH. Non-partner violence against women who use drugs in San Francisco. Violence Against Women. 2014;11: 1285-98.

15. Hirsch JS. Labor migration, externalities, and ethics: theorizing the meso-level determinants of HIV vulnerability. Soc Sci Med. 2014;100:38-45.

16. Stith SM, Smith DB, Penn CE, Ward DB, Tritt D. Intimate partner physical abuse perpetration and victimization risk factors: a meta-analytic review. Aggress Violent Behav. 2004;10(1):65-98.

17. Miller LE, Cater ÅK, Howell KH, Graham-Bermann SA. Perpetration patterns and environmental contexts of IPV in Sweden: relationships with adult mental health. Child Abuse Negl. 2014;38(1):147-58.

18. Moore TM, Stuart GL, Meehan JC, Rhatigan DL, Hellmuth JC, Keen SM. Drug abuse and aggression between intimate partners: a meta-analytic review. Clin Psychol Rev. 2008;28(2):247-74.

19. Fulu E, Jewkes RK, Roseli T, Garcia-Moreno C. Prevalence of and factors associated with male perpetration of intimate partner violence: findings from the UN multi-country crosssectional study on men and violence in Asia and the Pacific. Lancet. 2013;1:e187-207.

20. Pavao J, Alvarez J, Baumrind N, Induni M, Kimerling R. Intimate partner violence and housing instability. Am J Prev Med. 2007;32(2):143-6.

21. El-Bassel N, Gilbert L, Shaw SA, et al. The silk road health project: how mobility and migration status inflence HIV risks among male migrant workers in Central Asia. PLoS One. 2016;3.

22. Weine SM, Kashuba AB. Labor migration and HIV risk: a systematic review of the literature. AIDS Behav. 2012;16(6): 1605-21.

23. Raj A, Santana C, La Marche A, Amaro H. Perpetration of intimate partner violence associated with sexual risk behaviors among young adult men. Am J Public Health. 2006;96(10):1873-8.

24. Weine S, Bahromov M, Loue S, Owens L. Trauma exposure, PTSD, and HIV sexual risk behaviors among labor migrants from Tajikistan. AIDS Behav. 2012;16(6):1659-69.

25. Lawrence AE, Taft CT. Shame, post-traumatic stress disorder, and intimate partner violenc. Aggress Violent Behav. 2013;18(2):191-4. 
26. Crane CA, Hawes SW, Devine S, Easton CJ. Axis 1 psychopathology and the perpetration of IPV. J Clin Psychol. 2014; 70(3):238-47.

27. Straus MA, Hamby SL, Boney-McCoy S, Sugarman DB. The Revised Conflict Tactics Scales (CTS2): development \& preliminary psychometric data. J Fam Issues. 1996;17:283316.

28. Committee on Statistics. Ministry of National Economy of the Republic of Kazakhstan; 2014.

29. Goodman LA, Corcoran C, Turner K, Yuan N, Green BL. Assessing traumatic event exposure: general issues and preliminary findings for the Stressful Life Events Screening Questionnaire. J Trauma Stress. 1998;11(3):521-42.

30. Bohn MJ, Babor TF, Kranzler HR. The alcohol use disorders identification test (AUDIT): validation of a screening instrument for use in medical settings. J Stud Alcohol. 1995;56(4):423-32.

31. Derogatis L, Savitz K. The SCL-90-R, Brief Symptom Inventory, and matching clinical rating scales. In: Maruish ME, editor. The use of psychological testing for treatment planning outcomes assessment. 2nd ed. Mahwah: Lawrence Erlbaum Associates; 1999.

32. Boulet J, Boss MW. Reliability and validity of the Brief Symptom Inventory. Psychol Assess. 1991;3(3):433-7.

33. Vaglio J, Conard M, Poston WS, O'Keefe J, Haddock CK, House J, et al. Testing the performance of the ENRICHD Social Support Instrument in cardiac patients. Health Qual Life Outcomes. 2004;2(1):24.

34. Somach S, Rubin D. Gender Assessment USAID/Central Asian Republics. Kazakhstan: USAID; 2010. 